\title{
DEVELOPMENT AND VALIDATION OF HPLC METHOD FOR THE SIMULTANEOUS DETERMINATION OF ENALAPRIL MALEATE IN PRESENT OF THEIR IMPURITIES: APPLICATION TO TABLET ANALYSIS
}

\section{LILIYA LOGOYDA ${ }^{1 *}$, AHMED M. ABDEL-MEGIED ${ }^{2}$, YULIYA KONDRATOVA ${ }^{3}$, OLENA TROFIMENKO요 ${ }^{3}$ DMYTRO KOROBKO ${ }^{1}$, IRYNA DAKHYM ${ }^{4}$}

1Pharmaceutical Chemistry Department, Pharmaceutical Faculty, I. Horbachevsky Ternopil State Medical University, Ternopil City, Ukraine, ${ }^{2}$ Pharmaceutical Analytical Chemistry Department, Faculty of Pharmacy and Pharmaceutical Manufacturing, Kafrelsheikh University, Kafrelsheikh City, Egypt, ${ }^{3}$ Central R and D Laboratory JSC Farmak, Kyiv City Ukraine, ${ }^{4}$ Pharmacognosy and Medical Botany Department, Pharmaceutical Faculty, I. Horbachevsky Ternopil State Medical University, Ternopil City, Ukraine Email: logojda@tdmu.edu.ua

Received: 27 Sep 2017, Revised and Accepted: 28 Nov 2017

ABSTRACT

Objective: A simple, rapid, economical, and highly sensitive stability-indicating HPLC method was developed and fully validated for determination of enalapril maleate in presence of its related substances namely enalaprilat dihydrate and diketopiperazine.

Methods: Chromatographic separation was achieved on Grace Platinump C8 EPS column (4.6 mm i.d. X $250 \mathrm{~mm}, 5 \mu \mathrm{m})$ at room temperature. The mobile phase consisted of acetonitrile: $20 \mathrm{mmol}$ phosphate buffer adjusted to pH $2.2(25: 75 \mathrm{v} / \mathrm{v})$ isocratically pumped at a flow rate $2 \mathrm{ml} / \mathrm{min}$ and UV-detection was monitored at $215 \mathrm{~nm}$.

Results: The proposed method was validated according to ICH guidelines with total run time less than 9 min. The correlation coefficient ( $\mathrm{r}^{2}$ ) was noted as 0.99981 which states that the method was good linear to the concentration versus peak area responses. The developed method found to be high sensitivity with LOD and LOQ of 0.021 and $0.062 \%$; respectively. The developed, validated method was successfully applied for the determination of enalapril maleate in presence of their impurities in tablet dosage form.

Conclusion: A rapid, economical, simple and sensitive HPLC method was developed and validated for the determination of enalapril maleate in tablet dosage form in presence of their impurities. The developed method can help research studies, quality control and routine analysis with lesser resources available. Therefore, the proposed validated method is fast and reliable and can be used for routine quantitative analysis as well as quality control of enalapril maleate in pharmaceutical formulation.

Keywords: Enalapril maleate, Enalaprilat dihydrate, High-Performance Liquid Chromatography, Validation, ICH guidelines

(C) 2018 The Authors. Published by Innovare Academic Sciences Pvt Ltd. This is an open access article under the CC BY license (http://creativecommons.org/licenses/by/4.0/] DOI: http://dx.doi.org/10.22159/ijap.2018v10i1.22805

\section{INTRODUCTION}

Enalapril maleate is chemically described as $(2 \mathrm{~S})-1-[(2 \mathrm{~S})-2-[[(1 \mathrm{~S})-1-$ (Ethoxycarbonyl)-3-phenylpropyl] amino] propanoyl] pyrrolidine-2carboxylic acid (Z)-butenedioate (fig. 1). Enalapril maleate is a prodrug which metabolized rapidly in the liver to ethyl ester of a long-acting enalaprilat which inhibits angiotensin-converting enzyme (ACE) in human subjects and animals. ACE is a peptidyl dipeptidase that catalyzes the conversion of angiotensin I to the vasoconstrictor substance, angiotensin II. Angiotensin II also stimulates aldosterone secretion by the adrenal cortex. The beneficial effects in hypertension and heart failure appear to result primarily from suppression of the renin-angiotensin-aldosterone system. Inhibition of ACE results in decreased plasma angiotensin II, which leads to decreased vasopressor activity and to decrease aldosterone secretion [1].

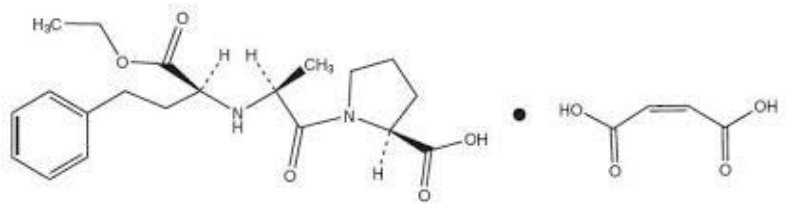

Fig. 1: Chemical structure of enalapril maleate

A literature survey was conducted and several methods were reported for the determination of enalapril maleate including the following methods: UV-Visible spectrophotometry [2-4], HPLC [5-13], HPTLC [14] and LC-MS/MS [15-17]. Previous reported method showed long retention time for enalapril maleate $(9.7 \mathrm{~min})$. However, no rapid and sensitive HPLC for the determination of enalapril maleate in its tablet dosage form. It was necessity to develop a shorter run time assay method for the determination of enalapril maleate tablets which lead to decrease in coast of analysis and reliable method to be used in quality control laboratories. The HPLC method for determination of enalapril maleate and related substances is official in European Pharmacopoeia (EP) [18]. Meanwhile, the reported method suffers from some drawbacks such as column oven should be thermostated at $70{ }^{\circ} \mathrm{C}$ lead to variation with different instruments. In addition, maximum limit of column oven temperature is $65{ }^{\circ} \mathrm{C}$ only for Waters and Shimadzu. On contrary, this novel proposed work represents a new HPLC method which is capable of separating all impurities with high resolution at room temperature getting more superior to the existing monograph methods. However, it was necessary to develop a simple, rapid, economical and sensitive HPLC for the determination of impurities in enalapril maleate in tablet dosage form.

\section{MATERIALS AND METHODS}

\section{Chemicals and reagents}

Enalapril maleate, enalaprilat dihydrate, diketopiperazine were obtained as a gift from Farmak pharmaceuticals (Kiev, Ukraine). HPLC grade acetonitrile, sodium dihydrophosphate dihydrate, phosphoric acid were obtained from Merck pharamaceticals.

\section{Instrumentation and chromatographic conditions}

HPLC system equipped with Agilent 1260, Grace Platinump C8 EPS column ( $4.6 \mathrm{~mm}$ i.d. X $250 \mathrm{~mm}, 5 \mu \mathrm{m}$ ). Chromatographic separation was carried out at ambient temperature $\left(22^{\circ} \mathrm{C}-25^{\circ} \mathrm{C}\right)$. All analytes were separated isocratically with a mobile phase consisting of 
acetonitrile and phosphate buffer $\mathrm{pH} 2.2(25 / 75, v / v)$, at a flow rate $2.0 \mathrm{ml} / \mathrm{min}$ with injection volume $50 \mu \mathrm{L}$. The effluent was monitored spectrophotometrically at $215 \mathrm{~nm}$.

\section{Preparation of mobile phase}

To prepare buffer solution $\mathrm{pH}$ 2.2.: $3.59 \mathrm{~g}$ of sodium dihydrophosphate dihydrate was dissolved in $1800 \mathrm{ml}$ of water, was fixed the $\mathrm{pH}$ of the solution to the value $(2.2 \pm 0.05)$ with phosphoric acid and then was added the volume of the solution with water $\mathrm{R}$ to $2000.0 \mathrm{ml}$ and was mixed.

\section{Stock standard solutions}

$20 \mathrm{mg}$ of the standard enalapril maleate was dissolved in mobile phase, was added $0.5 \mathrm{ml}$ of enalaprilat dihydrate with a concentration of $0.4 \mathrm{mg} / \mathrm{ml}$ and $2.0 \mathrm{ml}$ of diketopiperazine at a concentration of $0.4 \mathrm{mg} / \mathrm{ml}$ then was adjusted to a volume of 100.0 $\mathrm{ml}$ with the same solvent.

\section{Procedures}

The standard solutions were prepared by dilution of the stock standard solution with mobile phase. Triplicate $50.0 \mu \mathrm{L}$ injections were made for each concentration and chromatographed under the condition described above. The peak area of each concentration was plotted against the corresponding concentration to obtain the calibration graph and regression equation was computed.

\section{Analysis of dosage form}

Accurately weighed twenty Enalozid® tablets and average weight was calculated. A powder equivalent to $10 \mathrm{mg}$ of enalapril maleate was transfered into a $50 \mathrm{ml}$ volumetric flask. $30 \mathrm{ml}$ phosphate buffer solution ( $\mathrm{pH}$ 2.2) was added and sonicated for $15 \mathrm{~min}$. Solvent (buffer solution $\mathrm{pH}$ 2.2) was adjusted up to the mark. The solution was filtered using $0.45 \mu \mathrm{m}$ nylon filter. The amount present in the tablet was calculated from plotted calibration graph or utilizing regression equation. After setting the chromatographic conditions and stabilizing the instrument to obtain a steady baseline, the sample solution was loaded in the $50 \mu \mathrm{l}$ fixed sample loop of the injection port. The concentration of the solution is $0.2 \mathrm{mg} / \mathrm{ml}$. The comparison solution for the calculation of impurities is prepared from the solution of the preparation, obtaining a concentration of $0.02 \mathrm{mg} / \mathrm{ml}$.

\section{Method validation}

Once the chromatographic and the experimental conditions were established, the method was validated according to ICH Q2 (R1) guidelines [19].
System suitability tests have been checked by injecting different concentrations of enalapril maleate and related substances working standard and separation factor was monitored throughout the validation process.

Specificity of an analytical method is its ability to measure accurately and specifically the analyte of interest without interference from placebo and degradation products. The specificity of the method was established by injecting blank, placebo and standard solution in triplicate and recording the chromatograms.

Linearity of the detector response was applied by preparing calibration sample solutions starting with LOQ concentration. Each set of solutions were prepared in triplicates and analyzed for three successive days. Sample concentration and areas were used by plot calibration curves, the $\%$ RSD and Y-intercept of the calibration curves were computed.

Limit of detection is the lowest concentration in a sample that can be detected, but not necessarily quantified under the stated experimental conditions. The limit of quantitation is the lowest concentration of analyte in a sample which can be quantitatively determined with suitable precision and accuracy.

LOD and LOQ were determined at a signal to noise ratio LOD $=3.3$ $\sigma / \mathrm{S}$ and LOQ $=10 \sigma / \mathrm{S}$, where $\sigma$ is the standard deviation of intercept, $\mathrm{S}$ is the slope derived from calibration curve.

\section{RESULTS AND DISCUSSION}

\section{Method development and optimization}

The proposed HPLC method was developed to provide specific procedure for the rapid quality control analysis [20, 21]. This method provides high sensitivity for determination of enalapril maleate in presence of their impurities. To find the appropriate HPLC conditions, various columns, isocratic and gradient mobile phase systems were tried, and successfully attempts were performed using Grace Platinump C8 EPS column ( $4.6 \mathrm{~mm}$ i.d. X 250 $\mathrm{mm}, 5 \mu \mathrm{m}$ ) and mobile phase consists of acetonitrile and phosphate buffer solution $(\mathrm{pH} 2.2)$ in the proportion $(25 / 75, v / v)$, at a flow rate of $2.0 \mathrm{ml} / \mathrm{min}$ with UV detection at $215 \mathrm{~nm}$. Typical chromatogram (fig. 2), which shows a clear separation between the peaks of API, admixtures and placebo. The optimum chromatographic conditions and system suitability parameters are tabulated in table 1 .

Previous reported method showed long retention time for enalapril maleate $(9.7 \mathrm{~min})$. Upon comparison with our present work; a shorter run time assay method was developed for the determination of enalapril maleate tablets which lead to decrease in cost of analysis and reliable method to be used in quality control laboratories.

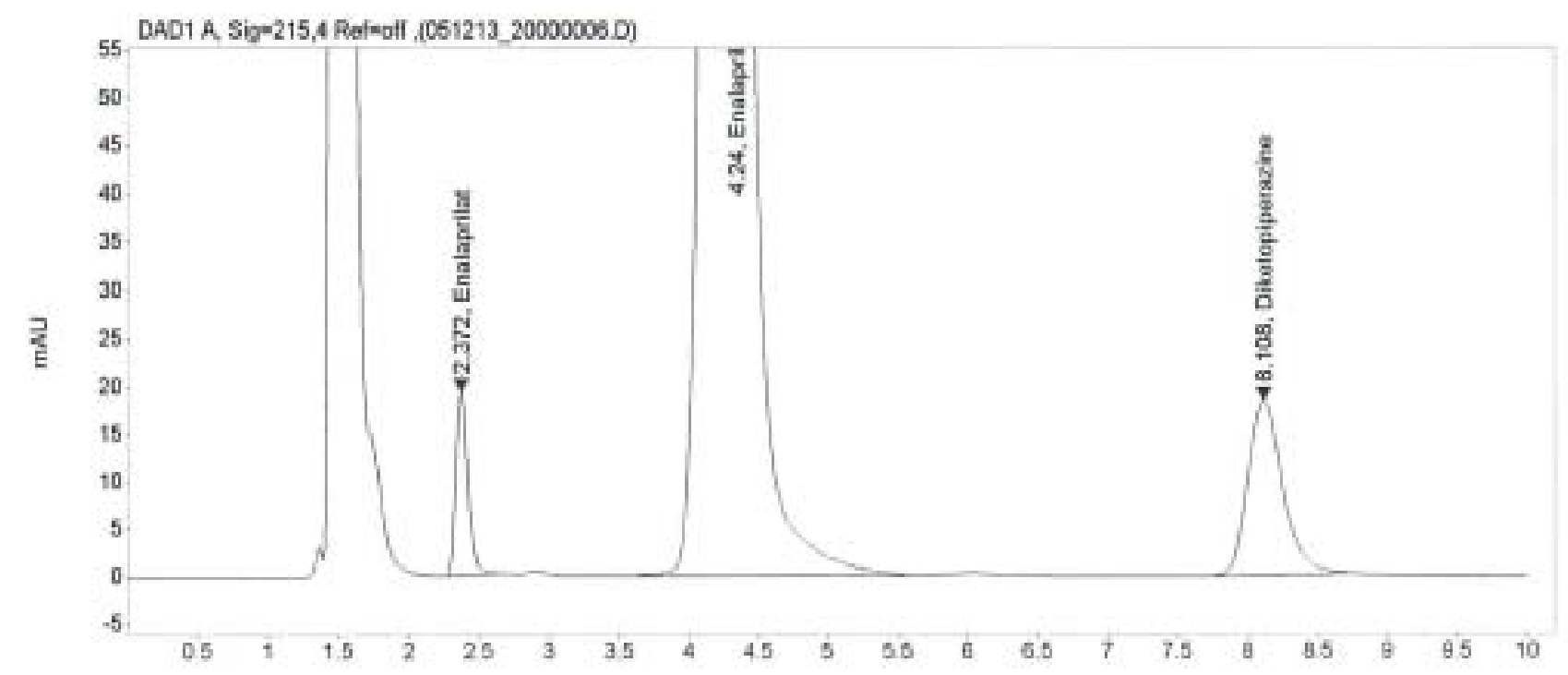

Fig. 2: Representative HPLC chromatogram of enalapril maleate $(0.02 \mathrm{mg} / \mathrm{ml})$ in presence of enalaprilat dehydrate and diketopiperazine using UV detection at $215 \mathrm{~nm}$ 
Table 1: Optimized chromatographic conditions

\begin{tabular}{ll}
\hline Parameter & Chromatographic conditions \\
\hline Instrument & Agilent 1260 \\
Column & Grace Platinump C8 EPS column $(4.6 \mathrm{~mm}$ i.d. X 250 mm, $5 \mu \mathrm{m})$ \\
Mobile phase & acetonitrile and buffer solution pH $2.2(25 / 75, \mathrm{v} / \mathrm{v})$ \\
Flow rate & $2.0 \mathrm{ml} / \mathrm{min}$ \\
Detection wavelength & $\mathrm{UV}$ at $215 \mathrm{~nm}$ \\
Runtime & $10 \mathrm{~min}$ \\
Column temperature & $30^{\circ} \mathrm{C}$ \\
Volume of injection loop & $50 \mu \mathrm{l}$ \\
\hline
\end{tabular}

\section{System suitability}

According to the requirements of the methods, the chromatographic system is considered suitable if such conditions are satisfied for the chromatographic results of the reference solution:

$>$ The actual absolute retention time of enalapril maleate peak should be about $4.4 \mathrm{~min}$;

$>$ The actual relative retention time, with respect to enalapril maleate peak, should be about 0.5 for enalaprilat dihydrate peak and about 1.9 for diketopiperazine.

According to validation data obtained for the reference solution, the parameters of the chromatographic system were:

$>$ The actual absolute retention time of enalapril maleate peak is 4.24 min;

$>$ The actual relative retention time, with respect to enalapril maleate peak of about $2.37 / 4.24=0.56$ for enalaprilat dihydrate peak and about 8.11/4.24 =1.91 for peak of diketopiperazine.

Thus, the parameters of the chromatographic system required by both methods for carrying out the validation experiment were sustained.

\section{Method validation}

\section{Linearity}

Under the above described experimental conditions, the linearity of the proposed HPLC method was investigated by analyzing a series of different concentrations by plotting the peak area against the concentration of standard drugs. The results of chromatographic determination of model solutions are present in table 2.

The calibration plot and characteristics of the linear dependence presented in (fig. 3 and table 3 ).

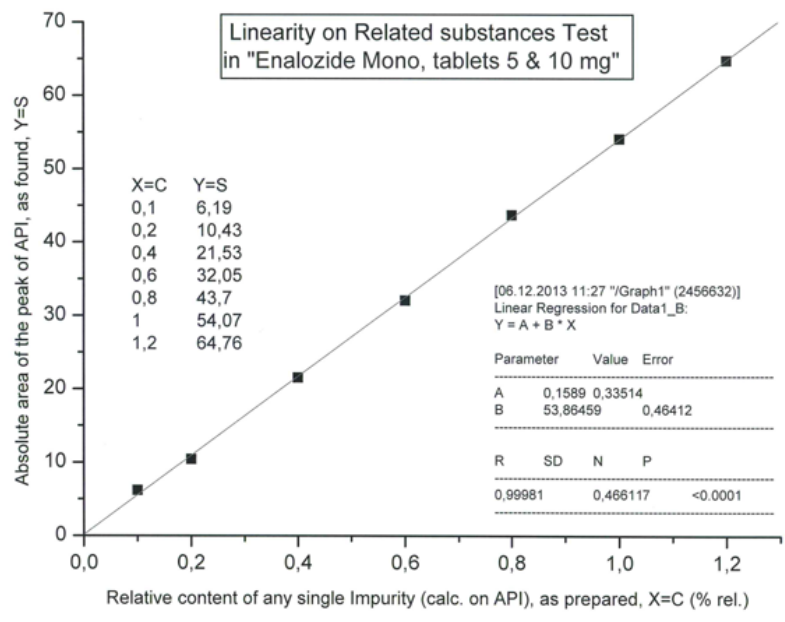

Fig. 3: The calibration curve for enalozide mono tablets

Table 2: Chromatographic determination of model solutions of enalapril maleate and solution (Enalozid_RS_d_1\%)

\begin{tabular}{|c|c|c|c|c|}
\hline Model solutions & $(\mathrm{Ci} / \mathrm{Ctest}) \times 100 \%$ & $S_{i}$ parallel measurements & Average $S_{i}$ & $\mathrm{RSD}_{\mathrm{i},}, \%$ \\
\hline \multirow[t]{3}{*}{ MS1 } & 0.10 & 6.04 & 6.19 & 5.10 \\
\hline & & 5.98 & & \\
\hline & & 6.55 & & \\
\hline \multirow[t]{3}{*}{ MS2 } & 0.20 & 10.57 & 10.43 & 3.25 \\
\hline & & 10.04 & & \\
\hline & & 10.66 & & \\
\hline \multirow[t]{3}{*}{ MS3 } & 0.40 & 21.69 & 21.53 & 1.20 \\
\hline & & 21.23 & & \\
\hline & & 21.66 & & \\
\hline \multirow[t]{3}{*}{ MS4 } & 0.60 & 32.19 & 32.05 & 0.39 \\
\hline & & 31.95 & & \\
\hline & & 32.02 & & \\
\hline \multirow[t]{3}{*}{ MS5 } & 0.80 & 43.42 & 43.70 & 0.84 \\
\hline & & 43.56 & & \\
\hline & & 44.11 & & \\
\hline \multirow[t]{3}{*}{ MS6 } & 1.00 & 54.24 & 54.07 & 0.73 \\
\hline & & 53.62 & & \\
\hline & & 54.35 & & \\
\hline \multirow[t]{3}{*}{ MS7 } & 1.20 & 64.32 & 64.76 & 0.68 \\
\hline & & 64.75 & & \\
\hline & & 65.19 & & \\
\hline \multirow[t]{5}{*}{ Solution (Enalozid_RS_d_1\%) } & 1.20 & 53.55 & 53.82 & 0.63 \\
\hline & & 53.96 & & \\
\hline & & 54.20 & & \\
\hline & & 53.76 & & \\
\hline & & 54.15 & & \\
\hline
\end{tabular}

*Average of 3 determinants, $\mathrm{SD}=\mathrm{Standard}$ deviation, $\mathrm{RSD}=$ Relative standard deviation 
Table 3: Characteristics of the linear dependence

\begin{tabular}{ll}
\hline The name of the quantity & Value \\
\hline$B$ & 53.86459 \\
$S_{B}$ & 0.46412 \\
$A$ & 0.1589 \\
$S_{A}$ & 0.33514 \\
$S_{R}$ & 0.466117 \\
$S_{R} / B$ & 0.008654 \\
$R$ & 0.99981 \\
\hline
\end{tabular}

The results obtained were processed by the least squares method. The correlation coefficient $\left(\mathrm{r}^{2}\right)$ was noted as 0.99981 which states that the method was good linear to the concentration versus peak area responses. The results show that a phenomenal relationship between peak area and concentration of the drug in the calibration curve. Results indicate high sensitivity of the proposed HPLC method.

\begin{abstract}
Specificity
Commonly used tablet excipients did not interfere with the proposed method. It was shown that there is no interference between the peaks of the potential admixtures taken into account with each other and with the peak of the API (table 4)-i.e.
\end{abstract}

Table 4: Specificity study

\begin{tabular}{ll}
\hline Name of the solution & Retention time $\left(\mathbf{t}_{\mathbf{R}}\right) \mathbf{m i n}$ \\
\hline Mobile phase & No peaks \\
Placebo & No peaks \\
Buffer solution pH 2.2 & No peaks \\
Enalapril maleate & 4.24 \\
Enalaprilat dehydrate & 2.37 \\
Diketopiperazine & 8.11 \\
\hline
\end{tabular}

The technique is specific for any single impurities. The placebo solution as well as sample solution of enalapril maleate tablets was analyzed as per proposed method and it was found that there was no interference of excipients with the enalapril maleate peak.

The peak purity of enalapril maleate peak was checked in the sample solution spiked with known related substances of enalaprilat dihydrate and diketopiperazine. Furthermore, the well shaped peaks also indicate the specificity of the method.

\section{LOD and LOQ}

LOD and LOQ were estimated a single to noise ratio of $3.3 \mathrm{\sigma} / \mathrm{S}$ and $10 \sigma / \mathrm{S}$ where $\sigma$ is the standard deviation of intercept, $\mathrm{S}$ is the slope derived from calibration curve.

Limit of detection $(\mathrm{LOD})=3.3 \times \mathrm{s}_{\mathrm{A}} / \mathrm{B}=3.3 \times 0.33514 / 53.86459=0.021 \%$

Limit of quantitation $(\mathrm{LOQ})=10 \times \mathrm{s}_{\mathrm{A}} / \mathrm{B}=10 \times 0.33514 / 53.86459=0.062 \%$

The LOD and LOQ values are presented in table 5 .

Table 5: LOD and LOQ of the proposed HPLC method for enalapril maleate

\begin{tabular}{lc}
\hline Limit of Detection (LOD) & $0.021 \%$ \\
Limit of Quantitation (LOQ) & $0.062 \%$ \\
\hline
\end{tabular}

The developed method found to be high sensitivity with LOD and LOQ of 0.021 and $0.062 \%$; respectively. The results of LOD and LOQ supported the sensitivity of the proposed method. Summary of validation presents in table 6 . The developed, validated method was successfully applied for the determination of enalapril maleate in presence of their impurities in tablet dosage form.

Table 6: Summary of validation

\begin{tabular}{|c|c|c|c|}
\hline $\begin{array}{l}\text { Validation } \\
\text { characteristics }\end{array}$ & Requirements & Validation result & Compliance \\
\hline Specificity & $\begin{array}{l}\text { Absence of interference of the peaks of the potential } \\
\text { admixtures taken into account with each other and with } \\
\text { the API peak }\end{array}$ & $\begin{array}{l}\text { Have showen absence of interference of the } \\
\text { peaks of the potential admixtures taken into } \\
\text { account with each other and with the API peak }\end{array}$ & Performed \\
\hline $\begin{array}{l}\text { Range of } \\
\text { application }\end{array}$ & $\begin{array}{l}\text { Limits of study ranges for any single impurity are defined } \\
\text { as } 0.10-1.20 \% \text { with respect to the nominal }(200 \mu \mathrm{g} / \mathrm{ml}) \\
\text { concentration of enalapril maleate in the test solutions. }\end{array}$ & $\begin{array}{l}\text { It was studied in the indicated concentration } \\
\text { limits for linearity, the limit of detection and the } \\
\text { limit of quantitation }\end{array}$ & Performed \\
\hline Linearity & $\begin{array}{l}\text { It should be confirmed by the least-squares statistical } \\
\text { method in the range of API application: } \\
R \geq 0,9950\end{array}$ & $\begin{array}{l}\text { Confirmed statistically in the range of } \\
\text { application: } \\
\mathrm{R}=0,9998\end{array}$ & Performed \\
\hline $\begin{array}{l}\text { Limit of Detection } \\
\text { (LOD) }\end{array}$ & $\begin{array}{l}\text { For any detectable single impurity: } \\
\text { Not more than } 32 \% \text { of the limit of } 0.1 \%\end{array}$ & $\begin{array}{l}\text { Found: } 0.021 \%<0.32 \times 0.1=0.032 \% \\
\text { Concerning the API }\end{array}$ & Performed \\
\hline Limit of & For any detectable single impurity: & Found: & Performed \\
\hline $\begin{array}{l}\text { Quantitation } \\
\text { (LOQ) }\end{array}$ & Not more than $0.1 \%$ & $\begin{array}{l}0.062 \%<0.1 \% \\
\text { Concerning the API }\end{array}$ & \\
\hline
\end{tabular}




\section{CONCLUSION}

A rapid, economical, simple and sensitive HPLC method was developed and validated for the determination of enalapril maleate in tablet dosage form in presence of their impurities. The developed method can help research studies, quality control and routine analysis with lesser resources available. Therefore, the proposed validated method is fast and reliable and can be used for routine quantitative analysis as well as quality control of enalapril maleate in pharmaceutical formulation.

\section{AUTHORS CONTRIBUTIONS}

All the authors have contributed equally.

\section{CONFLICT OF INTERESTS}

Declared none

\section{REFERENCES}

1. https://dailymed.nlm.nih.gov. [Last accessed on 20 Aug 2017]

2. Rahman N, Manirul HS. Optimized and validated spectrophotometric methods for the determination of enalapril maleate in commercial dosage forms. Anal Chem Insights 2008;3:31-43.

3. Manoranjani M, Karuna KK. UV-visible spectroscopic estimation and validation of enalapril maleate in bulk and pharmaceutical dosage forms. Int J Res Pharm Biomed Sci 2011;2:1651-6.

4. Sowjanya G, Gangadhar P, Rao RP, Subrahmanyam P, Suresh P. Simultaneous UV spectrphotometric estimation of enalapril maleate and hydrochlorothiazide in tablets. J Chem Pharm Res 2012;4:3483-8.

5. Stanisz B. Evaluation of stability of enalapril maleate in solid phase. J Pharm Biomed Anal 2003;31:375.

6. Santos EL, Souza KP, Da Silva ED, Batista EC, Martins PJF, Almeida VD, et al. Long term treatment with ACE inhibitor enalapril decreases body weight gain and increases life span in rats. Biochem Pharmacol 2009;78:951-8.

7. Al-Omari MM, Abdelah MK, Badwan AA, Jaber AMY, Mohan. Effect of the drug-matrix on the stability of enalapril maleate in tablet. J Pharm Biomed Anal 2001;25:831-902.

8. Gu ML, Strickley RG. A profound solvent effect on the diketopiperazine formation of the new dipeptide angiotensin converting enzyme inhibitor, Moexipril. Int J Pharm 1990;60:99-107.
9. Stanisz B. Kinetics of degradation of enalapril maleate in dosage forms. Acta Poloniae Pharm 2004;61:415-8.

10. Lima D, Dos Santos L, Lima E. Stability and in vitro release profile of enalapril maleate from different commercially available tablets: possible therapeutic implications. J Pharm Biomed Anal 2008;47:934.

11. Roskar R, Simoncic Z, Gartner A, Kmetec V. Stability of new potential ACE inhibitor in the aqueous solutions of different $\mathrm{pH}$. J Pharm Biomed Anal 2009;49:295.

12. Melander WR, Jacobson J, Horvath C. Effect of molecular structure and conformational change of proline-containing dipeptides in reversed phase chromatography. J Chromatography 1982;234:269-76.

13. Sciences Manindra Mohan, S Zafar Haider, Ankur K Anand, Amit $\mathrm{K}$ Srivastva. Validation of stability indicating HPLC method for the determination of enalapril maleate in tablet formulations. Int J Pharm Pharm 2011;3:180-3.

14. Mennickent SC, Rivas C, Vega MA, De Diego MD. A stability indicating HPTLC method for quantification of enalapril maleate in tablets. J Chilean Chem Soc 2013;58:1737-40.

15. Bhardwaj SP, Singh S. Study of forced degradation behavior of enalapril maleate by LC and LC-MS and development of a validated stability-indicating assay method. J Pharm Biomed Anal 2008;46:113-20.

16. Ghosh C, Jain I, Shinde CP, Chakraborty BS. Rapid and sensitive liquid chromatography/tandem mass spectrometry method for simultaneous determination of enalapril and its major metabolite enalaprilat, in human plasma: application to a bioequivalence study. Drug Testing Anal 2012;4:94-103.

17. Danafar H, Hamidi M. Liquid chromatography-tandem mass spectrometry (LC-MS) method for the assignment of enalapril and enalaprilat in human plasma; Pharm Biomed Res 2015;1:47-58.

18. European Pharmacopoeia. Enalapril maleate monograph. $8^{\text {th }}$ ed. European Department for the Quality of Medicines, Strasbourg, France; 2016. [Last accessed on 01 Jun 2017]

19. ICH Q2 (R1), Validation of analytical procedures, Text and methodology. International Conference on Harmonization, Geneva; 2005. p. 1-17.

20. Liliya Logoyda, Dmytro Korobko, Iryna Ivanusa, Kovalenko Serhii. Development of the methodology of the chromatographic determination of nifedipine in medicines. Asian J Pharm Clin Res 2017;10:149-52.

21. Raul SK, Aravelli AB, Jhansi D. RP-HPLC method development and validation for the simultaneous estimation of atorvastatin and ezetimibe in pharmaceutical dosage form. Asian J Pharm Clin Res 2015;8:178-81. 